\title{
Zwischen Macht und Ohnmacht
}

Hanna Möller

Rezension von Georg Eckert; Leonard Novy; Dominic Schwickert, (Hrsg.) (2013). Zwischen Macht und Ohnmacht Facetten erfolgreicher Politik.

Wie sieht erfolgreiche Politik im 21. Jahrhundert aus? Dieser Frage widmet sich der von Eckert, Novy und Schwickert in der Reihe „Politik als Beruf“ herausgegebene Sammelband „Zwischen Macht und Ohnmacht - Facetten erfolgreicher Politik“. Beobachtende Analysen finden sich in einem kritischen Nexus mit praktischen Erfahrungsberichten, nicht nur Theoretiker, sondern vor allem Politiker kommen zu Wort. Zu den Autoren gehören unter anderem Kurt Beck, Andrea Fischer, Gregor Gysi, Bodo Hombach, Sabine Leutheusser-Schnarrenberger, Franz Müntefering, Annette Schavan, Olaf Scholz, Gesine Schwan, Erwin Teufel, Stefan Collet, Oliver Liedtke und Henrik Schober.

Politikwissenschaftler prophezeien es seit geraumer Zeit: Die Mitgliederzahlen der Parteien gehen zurück, die Wahlbeteiligung sinkt, die traditionelle Parteienbindung gilt als antiquiert - es herrscht eine allgemeine Skepsis gegenüber politischer Entscheidungen und deren Repräsentanten. Skepsis sei an sich kein negatives Phänomen für die Demokratie, argumentieren die Herausgeber, und betonen den janusköpfigen Charakter des bürgerlichen Zweifels. Auf der einen Seite stelle er eine existentielle Gefahr für die Demokratie und deren moralische Grundlagen dar, auf der anderen Seite jedoch könne eine gesunde Skepsis die Bürger aktivieren und zur Partizipation anspornen. Es geht darum, in diesem Spannungsfeld ein Gleichgewicht herzustellen. Der vorliegende Sammelband untersucht Rahmenbedingungen und Erfolgsfaktoren, aber auch das sogenannte Zünglein an der Waage für den nicht immer ganz einfachen Balanceakt.

Im Zuge der Globalisierung trifft eine staatliche Regierung nicht mehr nur Entscheidungen für sich selbst, sondern beeinflusst Regierende und Regierte anderer Länder - sie befindet sich in einem Interdependenzverhältnis mit ihrem Umfeld. Während die wirtschaftliche, politische und sozio-kulturelle Vernetzung zur Grundbefindlichkeit der Moderne avanciert, sehen wir - etwas überspitzt formuliert - einer „Entstaatlichung“ der politischen Souveränität entgegen. Besonders deutlich wird dies am Beispiel der Umweltgesetzgebung: sorgsam gepflegte Naturgebiete sind nichtig, wenn das Nachbarland laisser faire gegenüber Umweltsündern walten lässt. Was sind heutzutage also noch „eigene“ Probleme, was wird uns extern aufgeladen? In dieser komplexen Welt steht die deutsche Politik vor neuen Herausforderungen, die in den Beiträgen des vorliegenden Werks auf anschauliche Art und Weise thematisiert werden.
Ohnmacht und Macht liegen eng beieinander. So untersucht der Sammelband, wie erfolgreiche Politik trotz erschwerter Rahmenbedingungen stattfinden kann. Das Buch kann und will kein Patentrezept für erfolgreiche Politik liefern, sondern sich dieser mit drei Kapiteln facettenartig annähern. Es handelt sich um Essays, in denen die Autoren versuchen, die Frage nach erfolgreicher Politik pointiert zu beantworten. Ein schwieriges Unterfangen, entzieht sich die Erfolgspolitik doch jeglicher Definition und kommt je nach Epoche und Kontext in anderer Ausprägung daher. Der Sammelband mit seinen vielseitigen Beiträgen sieht sich demnach eher als Einladung an die Leserschaft, über erfolgreiche Politikszenarien zu reflektieren und auf Grundlage dessen zu einem eigenen Politikverständnis zu gelangen.

Hierfür stellen die Herausgeber drei Kapitel zur Verfügung: Ziele und Werte, Mittel und Wege sowie Monolog und Dialog. Zu Beginn geht es um Motive der Politikgestaltung; mit Schlagworten wie Lernfähigkeit, Innovation und Führungsressourcen versuchen die Autoren die Triebfeder politischen Handelns auszumachen. So stellt beispielsweise Franz Müntefering in seinem Beitrag die Frage nach dem Politiker als Problemlöser. An das Kapitel Ziele und Werte anknüpfend setzen sich die Verfasser mit dem Handwerk erfolgreicher Politik auseinander und versuchen diese im politischen Spektrum zu verorten. In diesem Sinne offenbart Kurt Beck in seinem Essay Vom Handwerk guten Regierens Bekenntnisse eines Pragmatikers. Abschließend ist ein Kapitel der Kommunikation gewidmet. In Text, Kontext, Klartext werden Strategien und Nutzungspotenzial der klassischen Medien, aber auch der social medias analysiert. Insbesondere Stefan Collet, Oliver Liedtke und Henrik Schober versuchen den Politiker zwischen facebook Likes und Netzdiskussionen zu verorten und gehen neuen Möglichkeiten für neues Wissen in den social medias auf die Spur.

Der Sammelband streift zahlreiche Komponenten erfolgreicher Politik und betrachtet „Facetten statt bloßer Fassaden “. Es ist genau dieser prüfende Seitenblick, der das Buch vor einem normativen Zugang bewahrt und den Brückenschlag zu einer kritisch-reflexiven Auseinandersetzung ermöglicht.

In den Beiträgen werden Erlebnisse und Erfahrungen von Berufspolitikern dargestellt und geben somit Einblicke in eine ganz praktische Problembehandlung. Trotz dieses praxisnahen Ansatzes (oder gerade deswegen?) erfüllt der Sammelband alle wissenschaftlichen Kriterien und fungiert als gelungene Einstiegslektüre zum Thema erfolgreiche Politik.

Ein spannendes Sammelsurium an aktuellen Politikfragen, die auch morgen noch bewegen.

Hanna Möller

Universität Wien

hannamoeller.francultures@gmail.com 